\title{
University education in the shift of science \& technology paradigm towards global security and eco-technology
}

地球安全保障とエコテクノロジーへ向かう科学・技術パラダイムシフトにおける大学教育

\author{
Hirohisa UCHIDA \\ Department of Applied Physics, School of Engineering, Department of Research Promotion, Tokai University, \\ 1117 Kita-Kaname, Hiratsuka, Kanagawa 259-1292, JAPAN \\ FAX: +81-463-58-9461. E-mail:huchida@keyaki.cc.u-tokai.ac.jp \\ ( Received 28, September 1998 Accepted 19, January 1999 ) \\ The progress of science and technology(S\&T) is inducing tremendous changes in our perception to values. This \\ is yielding new issues which may never been solved with conventional way of S\&T. This fact should seriously \\ be taken into account in educational and research institutes. This paper discusses the paradigm shift of S\&T, \\ and points out the necessity of the incorporation of uncertain factors like sense of values of people into the S\&T \\ paradigm. A new concept, ECO (Environment Conscious) TECHNOLOGY towards the global and human \\ securities is suggested.
}

Keywords: science \& technology/paradigm shift/university education/eco-technology

\section{INTRODUCTION}

Educational reform is advancing at universities in Japan. This is the review of the Japanese educational policy in which great emphasis has been placed on catching up the cultures, and science and technology (S\&T) of Europe and U.S.A..

At the compulsory education levels, curricula and textbooks used at schools are standardized and controlled by the government. This system has been effective in nurturing people suitable for a group activity and working efficiently in an industrial society aiming at mass produces standardized goods.

At university education, the nurturing large numbers of engineers has played an essential role in the rapid industrial and economic development of Japan in the 70 s to 80 s. However, this manner adopted so far does not seem to work effectively in future because the society of Japan is forced to change itself in response to the changes in sense of values of people and the drastic change in international situations after the cold war.
As the introduction of this paper, the actual trend in the S\&T education at universities in Japan is briefly reviewed. Then, facts and issues coming from this review are argued in terms of the following subjects:

1) Review of S\&T education at universities in Japan

2) Diversification of sense of values and industrial structure

3) Shift of S\&T paradigm, and the necessity of the incorporation of uncertain factors such as sensibilities and sense of values into S\&T

4) Diversification and distribution in S\&T

5) From local to global security in the border less world: necessity of the concept - ECO-TECHNOLOGY

\section{SCIENCE AND TECHNOLOGY EDUCATION} AT UNIVERSITIES IN JAPAN ${ }^{1}$ 
Compared with universities in Europe, Japanese universities have placed more emphasis on industrial technology than basic science since the opening of Japan in 1868. This tendency can be confirmed by comparing, for instance, the number of researchers with doctor's and master's degrees in science and engineering fields(Table 1).

TABLE 1.The ratio of the number of researchers with doctor's/master's degrees in science to engineering for Japan, U.S.A., Germany and U.K.

\begin{tabular}{|c|c|c|c|c|}
\hline country & Japan & U.S.A. & Germany & U.K. \\
\hline years & $\begin{array}{lll}1976 \quad 86 & 91\end{array}$ & $1975 \quad 8690$ & 19758590 & $1975 \quad 8591$ \\
\hline Sc./Eng. & $\begin{array}{lll}0.3 & 0.3 & 0.3\end{array}$ & $\begin{array}{lll}1.2 & 0.5 & 0.5\end{array}$ & $\begin{array}{lll}2.5 & 2.8 & 1.5\end{array}$ & $1.4 \quad 1.4 \quad 1.5$ \\
\hline
\end{tabular}

In Japan like in U.S.A., the number of researchers with degrees in engineering surpasses those with science degree. This balance is reversed in Europe with traditional emphasis on basic science. Even by taking into consideration of the different systems in classifying academic departments in European universities, the data on this table clearly shows the difference in attitude towards education in Japan and Europe. This situation has not changed over the past 20 years. This means that education offered in Japan has traditionally and heavily centered around technology applications and their improvement.

A characteristic of Japanese universities is that the number of those who have completed 4 year university course is much greater than those with master's or doctor's degree. The significant contribution of these large numbers of bachelor engineers should be mentioned in improving productivity based on quality control(QC) by actually soiling their fingers at the production front. The situation seems quite different in Europe where the young people with higher education do not want to soil their fingers.

Changes are taking place within public and private sectors with emphasis on the study of basic research as a means of enhancing their international competitiveness, for example, through the collaboration among academic, industrial and governmental sectors. However, actual effect in the progress of basic science may not be expected very soon because the number of graduate course students in Japan is very small compared with those in U.S.A. and Europe(Table 2).

TABLE 2.The number of graduate course student per 1.000 population and the ratio of graduate to undergraduate students.

\begin{tabular}{|c|c|c|c|c|}
\hline country & Japan & O.S.A. & France & U.K. \\
\hline $\begin{array}{c}\text { the number of graduate } \\
\text { student/1,000 population }\end{array}$ & $\begin{array}{c}(1989) \\
0.7\end{array}$ & $\begin{array}{c}(1987) \\
7.1\end{array}$ & $\begin{array}{c}(1988) \\
2.9\end{array}$ & $\begin{array}{c}\text { (1987) } \\
2.2\end{array}$ \\
\hline graduate/undergraduate(Y) & 4.5 & 15.6 & 20.7 & 33.5 \\
\hline
\end{tabular}

In Japanese universities, the increase of the numbers of graduate course students and postdoctoral researchers is necessary in order to activate basic research. The improvement of scholarship system is a matter of great urgency. The Ministry of Education, Japan has placed emphasis on the investment of hardware rather than human software. In addition, the number of technical staffs in national research sectors has been decreased over twenty years. This indicates also that the Japanese Government ignores the essential role of technical staffs in research. The fact that research is made not by equipment but by man should be recognized. Otherwise, any creative research \& development nor future industrial development, which is competitive enough to the international markets, would be impossible.

The government is promoting to start venture businesses by nurturing venture capitals. However, social infrastructure including tax systems for venture and Europe where man can easily launch venture businesses.

Since 1980 , over $94 \%$ of junior high school graduates advance to high school(93\% for boys and $95 \%$ for girls in average), and about over $26 \%$ of Japan's high school graduates go on to study at 4-years course universities(35\% for boys and $16 \%$ for girls). When graduates to junior colleges with two years course are included, the ratio becomes over $36 \%$. 
The percentage of young people advancing to higher education levels is relatively high, however, personalities or individualities of young people are significantly ignored at schools. Emphasis is placed on the thinking and behavior as a member of a group. These young people, however, are asked suddenly to exhibit his or her own creativity in study and research at university and often at work in companies.

Generally speaking, this group oriented society may be closely connected with the traditional Japanese society with a characteristic of a community(Gemeinschaft) rather than a society(Gesellschaft). However, the compulsory education, which is standardized and rigidly controlled by the government, have been deliberately headed for the economic development based on the establishment of an industrial nation in which a group activity instead of personality or individuality has been emphasized. This after-effect is yielding serious problems at the university education and research for which creativity originated from individuality is vital. In Japan, the educational reform from elementary to high schools is a problem of great urgency for the promotion of creative S\&T. ${ }^{2}$

\section{DIVERSIFICATION OF SENSE OF VALUES AND INDUSTRIAL STRUCTURE}

The industrial system with the mass production of standardized goods had functioned well until Japan experienced the collapse of "bubble" economy in the 90 's. However, the diversified requirements of consumers are compelling industries to change their production philosophies from conventional mass produced standardized products to diversified products with smaller amounts and software functions which should be harmonized with spiritual and mental satisfactions based on each consumer's sensibility.

In response to this, industrial sectors are shifting their structures. Such movements may be easily made rather at small to medium(S\&M)-sized enterprises with less or no governmental control. Due to their high flexibility, successful cases can be seen in many venture businesses with computer software and original products with advanced technology.

A successful case of the governmental arrangement for S\&M-sized enterprises may be seen in the state of Baden-Wuerttemberg, Germany. The export of this state dominates $20 \%$ of the whole Germany's export, in recent years. Over $50 \%$ of GDP of this state is brought by the activity of S\&M-sized enterprises counting over $95 \%$ in the number of enterprise in this state. ${ }^{3}$

Continuous research and development(R\&D) of new technology and products are essential to keep up the ability competitive enough in the international and diversified consumers markets. The collaboration between S\&M-sized enterprises without their own R\&D groups and universities or local research sectors may be ideal in terms of personnel expenses for enterprises and research budgets for universities. Such collaborations should be taken into consideration in the R\&D strategy.

\section{SHIFT OF S\&T PARADIGM ${ }^{4.5}$}

Since the Industrial Revolution, the S\&T paradigm was composed mainly of materials(M) and energy(E). In the past 20 years, remarkable advancement has been made in semiconductor materials and corresponding computer technologies, and in medical science and life science. This advancement yielded the components, information \& technology $(\mathrm{I})$ and life science(L), in addition to materials(M) and energy(E) in the S\&T paradigm(Fig.1). ${ }^{4,5}$

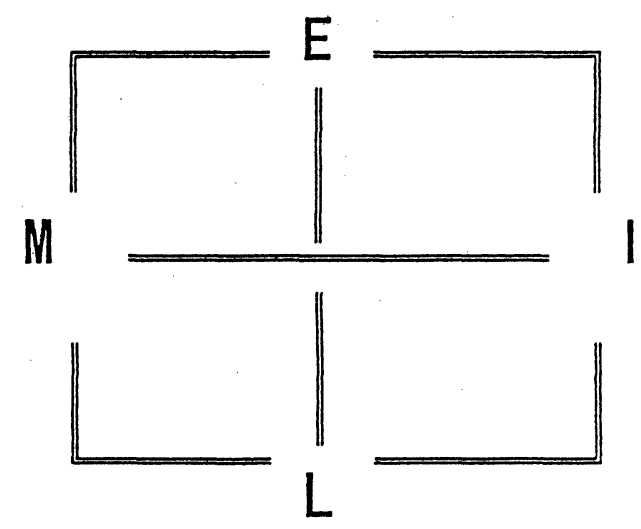

FIG.1. The paradigm of science and technology(S\&T) 4,5 
The impact of (I) was significant. For example, space satellites with many micro computerized sensors are going around the globe and are monitoring the surface of the globe for $24 \mathrm{~h}$ long a day and 365 days a year. By this global monitoring, we are able to be aware of global pollution, limited amounts of resources, the necessities of energy conservation, material recycling. The collapse of the wall in Berlin, the symbol of the end of the Cold War, was accelerated by the advancement of information \& communication technology.

However, with the advancement in computer technology, we are faced with new issues such as black boxed huge systems beyond human feeling, and manual or computer priority in an emergency control of high-tech jumbo jets.

If the Internet society develops, do we communicate only through computer display? On the other hand, the number of international travelers is increasing. What does this contradiction mean? The communication for business may be possible only through computer display. In spite of that, I am very skeptical about such a manner because we can get much more information through our five senses - seeing, hearing, smelling, tasting and touching. Human sensibility necessary for art, music, feelings and emotion may not be perfectly propagated through computer networks, though research is undertaken to build computers, with which we might feel as if we were at a site.

In the field of life science(L), we have contradictory issues. The pill may be used for birth control, resulting in the change in sexual morals. Birth control promoted in developing countries is based on economic levels, however, the promotion of birth control due to overpopulation sounds rather egocentric. We have to respect their own cultures and the fact that they need many people working with. Gene control technology should be used for incurable diseases like cancer and AIDS protections. However, gene technology might be used for human selection and breeding by test tube baby experiment. What is the definition of death based on heart or brain, meaning when and in what judgement the life support system of terminal patients should be shut down? These questions are closely related with each regional culture, religion and ethics, which have never been treated in the frame of conventional S\&T. At present, we are forced to incorporate these uncertain subjective factors such as cultural diversification and sense of values into S\&T, and which should be seriously considered in the S\&T education.

\section{V . DIVERSIFICATION AND DISTRIBUTION IN TECHNOLOGY}

Contrary to early expectations, downsized network computers for communication are overwhelmingly used rather than large computers for calculation. The growing internet society may yield an international economic society by cyber settlement as credit card companies have already started to examine the possibility of the cyber business.

The construction of huge systems like nuclear power stations should be minimized in terms of safety and controllability. In the utilization of renewable energy, low and intermittent energy densities of solar, wind and geothermal energy is converted to hydrogen and stored, with which energy can be highly densed. Several projects are undertaken using these diversified and distributed local energy systems.

In Japan, over $60 \%$ of the generated energy is radiated in air as waste heat. A test calculation suggests that if $10 \%$ of the wasted heat could be recovered, no additional construction of a nuclear power station may be needed. Thus, the integrated contribution of distributed elemental technologies is very effective.

The diversification and distribution of energy systems, and cogenarations with different energy sources will lead to the energy utilization at higher efficiencies, and which will reduce the productions of carbon dioxides and acid rains to improve global environment around us.

\section{BORDER LESS WORLD AND GLOBAL SECURITY}

The worldwide spread computer network makes it possible to communicate each other independent of distance and time, and the computer controlled large 
high-tech jumbo jets carry large numbers of people over the globe. In addition, space satellites can observe military bases and movements, nuclear power stations and their operating conditions, natural disasters, distribution of plankton, sea currents and their temperatures etc.

These advanced technologies are actually erasing the borders among nations, and the world is actually becoming border less.

Either through computer networks or by direct meetings, the interactions among various cultures and different sense of values will increase. These interactions, however, have a wide range from the change in fashion in Wien to the changes in political, economical and industrial structures in certain nations, or these interactions may become fatal as can be seen in religious conflicts in some areas as Europe has much experience in this respect.

In the border less world, the concept of security should change from the conventional to new one. ${ }^{6}$ The conventional security has been based on historical, military and economical relations. However, in the border less global society, the security should be considered as the total security, i.e., global security ${ }^{6}$ covering economic and social development, living standard, welfare and human rights. Issues such as global environment, population, foods, resources and energy are threatening our existence, and they are essential factors for the global security. Since these issues may be solved by certain science and technological way in future, the diversification of culture and sense of values should be taken into consideration in the global security as well as in S\&T.

\section{CONCLUDING REMARKS}

The Eco-Technology means a concept: the fusion of ecology and technology. Until quite recently, we had Egocentric (Ego-)Technology or Economic Technology. In my opinion, the Eco-Technology should mean a larger concept: ecological, social and cultural environment conscious-technology(Fig.2). ${ }^{7}$

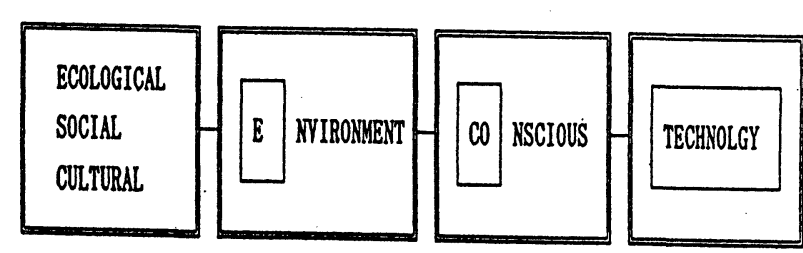

FIG.2. The concept of Eco-Technology ${ }^{7}$

The concept of the Eco-Technology may be realized only when human sensibilities, sense of values and the diversification in ecology, society and culture are considered as an interface to harmonize the relation between people and S\&T(Fig.3). ${ }^{7}$

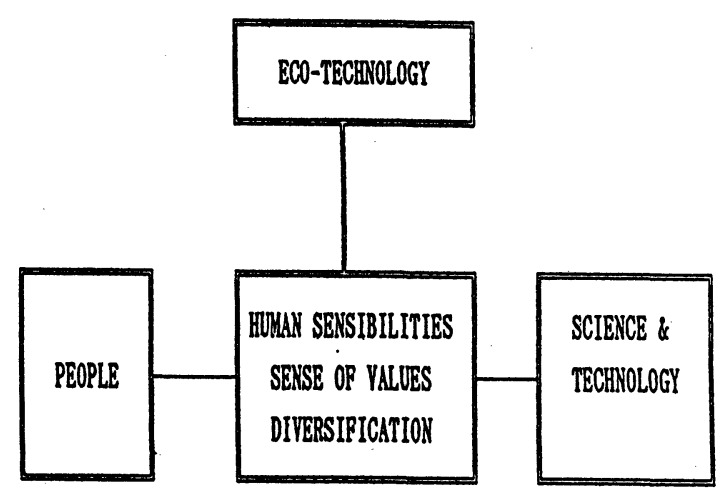

FIG.3. Realization of Eco-Technology

In the S\&T education, the changes in systems and curricula may not be effective. For the global security, the nurturing young people should be made in the emphasis on the promotion of high sensibilities and potentials to understand the significance of the diversified cultures and value judgements

\section{REFERENCES}

1 H.Uchida, "Japan's Science and Technology Advancement-Characteristics and Problems", Proc.EUROPALIA'89-JAPAN:Science \& Technology Symp., Berlin, Germany, Oct.1989,;Proc. published by the Honda Foundation and the EC-Joint Research Center, Dec.1990, p.7-11. 
${ }^{2}$ H.Uchida, "Creativity in Japanese and German Educations", Proc.Japan-German Symposium on Education, Nov.1992, by Tokai University Press, Nov.1993, ISBN 4-486-030966, p.143-145.

3 Information about "Baden-Wuerttemberg", Gesellschaft fuer Internationale Wirtschaftliche Zusammenarbeit, Baden-Wuerttemberg mbH, Stuttgart, Germany, data from 1993.

${ }^{4}$ H.Uchida, "Revolution in Materials Science Towards 21th Century", Japan-Taiwan Symposium,"Progress of Asia-Pacific Region and Science \& Technology-Issues For 21th Century" , Sep.1992, Taipei, Taiwan; Proc. published by the Honda Foundation and the Asia \& Pacific Council for Science \& Technology Association, June 1993, p.42-56.

${ }^{5}$ H.Uchida, "Role of University Education in the Paradigm Shift of Science \& Technology Towards Future",Proc.Int.Cong."LOMONOSOV-94", Oct., published by the University of Moscow, Russia, ISBN 5-88091- 006-7, p.148-152.

6 T.Matsumae and L.C.Chen, "Common Security in Asia-New Concept of Human Security(Eng.)", Tokai
University Press, ISBN 4-486-03102-4, 1995.

7 H.Uchida,"Role of University Education in the Development of Central Europe", Proc.Japan-Austria Seminar"Economic and Social Prospects for the CEFTA Countries in the Nineties and Beyond", Wien, Austria, June 1996, published by Bank Austria and the HONDA Foundation, p.96-103.

Biography of Hirohisa Uchida

Hirohisa Uchida was born in Tokyo, Japan, on 25 1949. He received the Ph.D.(Dr. rerum naturalium) in Metallurgy in 1977 from the University of Stuttgart, Germany. He has been professor at the department of Applied Physics, School of Engineering, Tokai University since 1981. He was the leader of the UCHIDA-Supermagnetic Materials Project, the Kanagawa Academy of Science \& Technology(KAST), Kawasaki, Japan, between 1990 and 1994. He has published 135 papers, 9 books, more than 50 newpaper articles and 12 patents, and received more than 20 invitations to give lectures at international scientific meetings including the Gordon Reseach Conferences. He is the Industrial Technology Council Committee Member of the Ministry of International Trade and Industry(MITI) and the Councilors of the HONDA Foundation and the Society of Advanced Science(SAS). He has been an executive director of the Department of Research Promotion, Tokai University since April 1997. 